\title{
The development of a sense of rhythm in students in the process of choral conducting training
}

\section{O desenvolvimento de um senso de ritmo nos alunos no processo de treinamento de regência coral}

\author{
(iD) Nan Xue 1 \\ Ningbo University, Ningbo, China \\ nanxue497@yahoo.com
}

\begin{abstract}
The purpose of this article is to study the effectiveness of pedagogical and psychological conditions that form a sense of rhythm in students involved in conducting. The study was conducted in 20172019 among 1-2 year students from Central Conservatory of Music in Beijing (China). In the control part of the experiment, $42 \%$ of students were in the group with a low level of rhythm perception. The number of students with a low level of intonation of musical rhythm was reduced by 2.0 times, a combined response as a key element of the conductor gestures of conducting was increased by 2.81 times.
\end{abstract}

Keywords: chorus; conducting; music education; rhythm.

Resumo: O objetivo deste artigo é estudar a eficácia das condições pedagógicas e psicológicas que configuram o senso de ritmo nos alunos ( $n=200$ ) envolvidos na regência. O estudo foi realizado em 2017-2019 entre alunos de um a dois anos do Conservatório Central de Música de Pequim (China). Na parte de controle do experimento, $42 \%$ dos alunos estavam no grupo com baixo nível de percepção do ritmo. O número de alunos com baixo nível de entonação do ritmo musical foi reduzido em

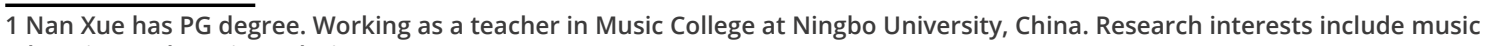
education and music analysis. 
2,0 vezes, uma resposta combinada como elemento chave dos gestos do maestro da regência foi aumentada em 2,81 vezes.

Palavras-chave: coral; regência; tecnologias emergentes; Educação musical; ritmo.

Submetido em 02.09.2020

Aceito em 19.11.2020 
The development of a sense of rhythm in students in the process of choral conducting... Nan Xue

\section{Introduction}

Conducting is one of the most sought-after professions in contemporary music using choral and orchestral elements (ChengKang, 2012).

The conductor may transfer his/her intentions to the orchestra or chorus in various ways. In particular, this is a speech message, a demonstration of playing an instrument, as well as conducting itself (Edwards, 2015). The combination of the application of these methods allows the conductor to explain his/her intentions to the musicians in an accessible and visual way (Handelsman, 2017).

A characteristic feature of the speech form of communication with musicians is its use exclusively at rehearsals (Holoman, 2012). At the rehearsal with the help of speech, the conductor explains to the musicians his/her intentions regarding the structure of the composition, its idea and content, as well as the filling of musical images. The techniques used by the conductor during speech communication are aimed at helping musicians find the most suitable playing methods, the technical features of the play of individual fragments of a musical composition, or how, in the opinion of the conductor, a piece should be performed (Hopper, 2015). More effective than speech is the demo method, when the conductor, using his/her example of playing a musical instrument, shows the musician how to play a piece. The specificity of music is that playing an instrument is a more effective means of demonstration compared to explanations. Both of these methods are applicable before the start of the play. During the play, the third method is applied - conductor gestures (Hamilton, 2014).

Regarding the latter method, there are many opinions about its execution or importance. Some consider it less important than the speech or demonstration method (Kramann, 2019), while others distinguish between different techniques and methods of performance (Edwards et al., 2019). Particular attention is paid to disputes over conducting technology (Desmet et al., 2012). For 
The development of a sense of rhythm in students in the process of choral conducting... Nan Xue

example, how correct or incorrect the technique of a particular conductor is, how much clocking schemes are used by him/her, to what extent the gestures of the conductor should be expressed sparingly, restraint or freely (Godøy, 2013). Should the conductor's gestures influence choir musicians or listeners too? The following question remains unclear: "How the gestures of the conductor affect musicians (Maes et al., 2015)?" The nature and means of expressing the conductor's gesture remain unclear. Conductors with a low level of conductor gestures are known, nevertheless, they achieve a high level of artistic results (Palmer, 2013). That is why there is an opinion that conductor gestures are not the most important element in the education of a conductor (Roze et al., 2015). This issue is highly debatable, since conductors with a low level of conductor gestures need a large number of rehearsals in order to achieve satisfactory results, in which a complete study of the piece being played is performed. In concert conditions, such conductors, as a rule, rely on the fact that the musicians from the orchestra (choir) already know all the details of the piece played, so their technique is limited only by meter and pace (Roze et al., 2018). Such a low level of conductor gestures can be excusable during rehearsals, in conditions of constant touring with a large team of musicians, well-known conductors must achieve fast and high-quality results using conductor gestures, since the number of rehearsals is minimal (Thompson and Luck, 2012).

It is difficult to evaluate the level of work of a conductor, most often, a person's professionalism depends on the individual him/ herself (Caldwell and Hayes, 2016). This is due to the fact that the movements of his/her hands are in no way connected with the instrumental part. Therefore, if the level of a musician or singer can be judged by their playing or singing, then such an assessment is difficult to make about a conductor. Nevertheless, the conductor, above all musicians from the choir or orchestra, is an object of close attention from the audience.

All these discrepancies complicate an adequate analysis of the features of conducting. Equally necessary is the development 
The development of a sense of rhythm in students in the process of choral conducting...

of a unified methodology for teaching conducting for students of musical universities.

Another, very important point for conducting education is the presence of asense of rhythminfuture musical conductors(Bonshor, 2016). The second, more important point, is the conductor's sense of composition's rhythmic pattern, like verbal images in literature (Black, 2014). The rhythm is directly related to the manual way of conducting, since it is its predecessor. The conductor, feeling the rhythm, through the manual method transfers his/her individual and professional sense of rhythm to the musicians and listeners. Thus, rhythm is the inner core of any musical composition, and the manual method is the external reflection of the conductor's sense of rhythm, aimed at musicians (as rhythm performers) and listeners (as observers).

The scientific and theoretical basis for solving many problems of pedagogy of music education is the intonation teaching of B.V. Asafiev (Khannanov, 2018). The study of his works allowed identifying the main aspects of the interaction of two principles of musical art: intonation and rhythm. In the theoretical concept of B.V. Asafiev, all the phenomena of music are intonational and do not exist otherwise, and the rhythm, therefore, also has an intonational character. Paying attention to the intonational nature of rhythm, the scientist emphasizes that rhythm and intonation are inseparable from each other, like the pulse beat and blood. Rhythm in unity with pitch is the main content of the musical flow, where intonation is welded with rhythm as a disciplining factor.

The study of the problems of 20th-century rhythm showed that the rhythm of modern music is distinguished by a variety of new techniques and compositions. Rhythm as a factor in the organization of musical time began to play a primary role. The content of the musical language has also become different. Along with the classical beat system, various modifications of the beat system became widespread, and new, non-beat forms of rhythmic organization began to be strengthened. The principle of the omnivisibility of the time unit arose. A rhythm with 
The development of a sense of rhythm in students in the process of choral conducting... Nan Xue

non-fixed durations appeared, where the temporal gradation was subordinated to the will of the performer. Other musical concepts underwent transformation along with the disappearance of such units as bar and time beat (Fomina, 2000). Thus, the issue of musical rhythm develops into a problem of musical timing. Absorbing the currents of expressiveness of melody and harmony, the rhythm is perceived as "a living system of impulses of expressiveness, unfolding in time" (V.P. Kholopova) and even as rhythmic energy.

The relevance of the study of musical-rhythmic development of students in conducting pedagogy is due to a number of prerequisites. First, the question of the importance of musical rhythm in the performance of a conductor has not been fully considered. In the works devoted to the art of conducting and pedagogy, only particular questions of the organization of rhythm are considered (McKay, 2015; Khannanov, 2018). Secondly, the features and pedagogical conditions of the development of the sense of rhythm in the process of the formation of the conducting technique have not been determined, namely: the corresponding forms of management of this process, using the intonational theory of rhythm and its motor nature. Thirdly, in spite of the fact that the main influence of the conductor on the performers is carried out with the help of the motor display of rhythmic structures, the available literature on various components of the art of conducting is limited, as a rule, to the analysis of timing schemes (Fomina, 2000). As a result, the practice of conducting has a number of unsolved problems that require further research. Thus, the identified problems in the field of mastering the conducting technique cause contradictions between the importance of rhythmic development for the theory and practice of conducting and the lack of theoretical and methodological substantiation of this process.

The problem of the research is to identify the conditions for the development of a sense of musical rhythm among university students in the process of individual teaching in conducting. The issue of the theory of musical rhythm is developed in many aspects (McQuere et al., 1983; Cross, 1998). In musicology, the theory of 
The development of a sense of rhythm in students in the process of choral conducting... Nan Xue

musical intonation occupies a worthy place, but in the content of musical theoretical disciplines, issues of the intonational nature of music do not find their proper development. The reason for this is the openness of the theory of musical intonation. Musical intonation is often understood substantively, as a contextual content-semantic function of a system element. Different types of tone relationships are considered as intonational structures, divided by levels of building relationships into simple, complex, integrated (Zak, 1982). The totality of intonation structures and processes of their interaction is defined as an intonation system. The intonational form of music is presented as a metasystem, the elements of which are local systems of harmony, musical form, musical texture, rhythm and melos.

Based on the foregoing, the urgent question is the theoretical aspect of the concept of rhythm for a young conductor and a small degree of its use in practice. In addition, there is no theoretical justification in the musical education of young conductors for the importance of understanding rhythm. The authors set the task of finding the most suitable conditions for increasing the effectiveness of the sense of rhythm among conservatory students who specialize in conducting and choral training.

Conducting and choral education as elements of music education are well developed in Western countries, but in China, despite the long history of musical traditions, this issue is not well developed. Choral art began to develop in China only in the second half of the last century. However, from that time there are already several works of Chinese composers recognized around the world (Chunyou by Li Shutong, Yuhou Caihong by Lu Zaiyi). In modern China, the art of conducting and the choral stage are developing unevenly; there are a number of unresolved issues. If in Western countries the Christian church had a decisive influence on the development of choral singing, then in China there was simply no dominant religion everywhere. Despite a large number of choirs (more than 500 throughout the country, and about 10 million participants), most of them consist of non-professionals. At primary 
The development of a sense of rhythm in students in the process of choral conducting...

and secondary schools in China there are choirs for young people, also, in addition to them, there are more professional choirs for the elderly (more than 1 thousand in Beijing). The general level of nonprofessionalism is associated with the lack of in-depth education in primary and secondary classes. Nevertheless, professional conductors and other musicians are united in a number of organizations, for example, the China Chorus Association, which:

- promotes the accumulation of knowledge about the choir and choral activities;

- raises choir standards;

- recommends choral works;

- strengthens the theory of the choir and academic research;

- promotes international exchange of choral arts and the development of choral art among various ethnic groups in China (Tang, 2020).

The development of choral art in China has a number of unresolved issues. 1. Small repertoire of musical works as an option for choirs. In this regard, there is no breakthrough in performances. Chinese folk music, usually performed by such choirs, is not entirely suitable for the repertoire. 2 . The lack of a sufficient level of performance to clearly express the feelings and the story behind the songs. 3. Excessive attention paid to national costumes, makeup, but not the technique of execution. Among the conductors, competitions for the selection of the best talents in China have been held relatively recently, since 2011, the most striking example is the International Conducting Competition for Chinese Music (Xinggui, 2019).

Recently, due to the shortage of specialists in China, there is an active training of musicians, choir members and conductors at the higher education level. The Central Conservatory of Music in Beijing and the Shanghai Conservatory are among the most famous universities where only high-level specialists are trained. Still, among Chinese students, research related to choral education and conducting is necessary. The key point in the study can be 
The development of a sense of rhythm in students in the process of choral conducting...

considered the activities of teachers, since their intervention has contributed to a significant improvement in the results of a group of students participating in the experiment.

The purpose of this study is to develop methods for effective development or improvement of a sense of rhythm among students of the specialty "choral conducting training". In this case, the object of the study is the very process of preparing students of the specialty "choral conducting training", and the subject of the study is the development of students' sense of rhythm during training.

In the process of research and data processing, the authors put forward the following hypothesis. For the successful development of a sense of rhythm in future conductors, a comprehensive approach is needed, including such elements of rhythm perception as sensory-emotional, intellectual, motor, as well as factors related to the psychophysiological perception of rhythm. The combination of these factors should contribute to the development of a sense of rhythm and enhance different techniques in conducting students. In this work, the authors approach the concept of rhythm as a manifestation of melodic intonation considering a melodic basis. All phenomena of music are intonational in nature, and, accordingly, the rhythm also has an intonational character. Thus, rhythm and intonation are inseparable, rhythm can serve as a disciplining factor for intonation. In modern music, rhythm plays a major role as a factor in the organization of musical time. Rhythms with nonfixed durations appeared, the role of measure and measure beat decreased, the issue of rhythm became one of the main issues when considering a musical work as a temporary process.

The authors admit that when the pedagogical process includes a new learning factor, namely, control over conductor's movements, it is possible to obtain results that are significantly different for the better. In the process of learning, students develop an understanding of rhythm as a multifaceted form of the temporal structure of music. At the same time, meter, tempo, and all rhythmic aspects are included in the rhythm development 
The development of a sense of rhythm in students in the process of choral conducting... Nan Xue

process, which can be realized only with the motor freedom of the body. A sense of music rhythm contributes to the adequate transfer of imaginative representations. Probably, such an approach can optimize the educational process in the conducting teaching system, and not only among Chinese students.

\section{Materials and methods}

\subsection{Materials}

Data collection was carried out during 2017-2019 at the Central Conservatory of Music in Beijing (People's Republic of China). The auditory-motor, as well as the intonation perception of rhythm by students was assessed. Junior students of 1-2 courses are selected, whose formation of musical skills has not yet been completed. The sample included students with successful performance indicators (grades higher than "satisfactory", that is, "good" and "excellent"). The group was supervised and the practical part of the proposed model was implemented by 10 university teachers (conducting specialty) in coordination with the authors of the article. An agreement on non-disclosure and confidentiality of information was signed with each participant, student and teacher. The study complied with all generally accepted ethical and moral standards. In total, 200 students were observed. The study included 100 men and 100 women, the average age of $19.5 \pm 0.7$ years. The size of this sample is statistically relevant because it exceeds the minimum number of 30 replicates.

Students were observed by the authors of this study during conducting lessons. At the same time, the authors' model was tested at conducting lessons that were based on the principle of individual lessons. During 2017, data were collected on student performance without taking into account the model; during 2018 and 2019, students were monitored at individual conducting lessons, 100 people a year. 
The development of a sense of rhythm in students in the process of choral conducting...

The research was carried out in accordance with international norms of ethics and morality. Each of the participants entered into a written agreement guaranteeing the observance of anonymity (non-disclosure of personal information about the participant), as well as the norms of ethics and morality. The students agreed to disclose the name of the institution in which the study was conducted. This study was approved at a meeting of the Ethics and Morality Committee of the Central Conservatory of Music in Beijing, Protocol No. 3, dated January 12, 2017. The decision of the committee was positive, since the members of the committee did not find any violations of ethics and human rights.

\subsection{Study design}

Mechanisms for controlling the motor process can be divided into three groups that act in combination:

1) sensory perception and intellectual-logical comprehension;

2) psychophysiological characteristics of an individual;

3) motor responses to auditory perception.

Only the combination of emotional, conscious and auditorymotor perception, their combined use will ensure the full implementation of the set task of rhythmic development. Here it is necessary to highlight the problem of an individual approach. The teacher needs to understand: a) the general cultural level of the individual; b) the student's musical and auditory inclinations; $c$ ) development of his/her motor system and emotional endowments; d) features of the higher parts of the central nervous system and the student's age.

The study of the theoretical and methodological foundations of the problem under study allowed developing a model for the development of a sense of musical rhythm in the process of mastering the conducting technique and characterizing its components. 
The development of a sense of rhythm in students in the process of choral conducting...

The main components of this model are:

1) organizational, which includes individual lessons, consultations, independent work of students, analysis of specific situations;

2) meaningful, providing for the formation of knowledge, skills, and abilities as the basis for the development of conducting techniques; emotional comprehension of all components of the musical rhythm and creative implementation of the composer's idea, aimed at embodiment of the musical image;

3) procedural, covering technologies and methods aimed at the practical development of conducting techniques and the implementation of the educational process in accordance with the principles of developing a sense of musical rhythm;

4) motivational component that contains values that determine the desire to master the conducting technique. The study substantiates the significance of each constituent model, its influence on the entire process of development of conducting techniques.

Within the framework of the procedural component, the main pedagogical principles necessary for the successful process of rhythmic development of novice conductors are outlined:

1) comprehension of rhythm as a living system of impulses of expressiveness, unfolding in time;

2) creation of a single complex of tempo and meter of rhythm;

3) the development of rhythm through the auditory-motor method, which includes the intonational theory of rhythm and its motor nature;

4) integration into a single emotional-auditory-motor complex of all spheres of rhythm perception with the dominant meaning of hearing;

5) the interaction of the motor and auditory process of perceiving a musical rhythm with a psychological setting, where 
The development of a sense of rhythm in students in the process of choral conducting...

the experienced artistic image should become the regulator of all actions.

These principles are based on the general laws of perception and development of musical rhythm as a psychophysiological, intellectual-rational and emotional process. Considering the problem of interrelationships between the components of the proposed model, it should be noted that the result of rhythmic development is determined by quantitative and qualitative changes in the sense of rhythm in the process of mastering the conducting technique. Quantitative changes consist in the fact that the student, in the process of studying, masters the sense of time and space, the sense of the accuracy of muscular efforts, the art of auditory impressions, which is conditioned by the meaningful activity of the human intellect. Qualitative changes are determined by the understanding of all the laws of musical sonority, including deep theoretical and practical knowledge for the implementation of the process of rhythmic development. As a result, an organic combination of rhythms of movement and rhythms of music should be developed, where the musical fabric itself prompts the conductor's gestures, organizing them in time, space, according to muscular efforts. All movements, in turn, will help expressively and as accurately as possible convey the entire musical and rhythmic image. The mechanism for implementing the developed model consists in a detailed study of all its components aimed at the final result: the formation of special professional competencies that contribute to the development of conducting techniques based on understanding the expressive essence of musical rhythm.

\subsection{Experiment}

To conduct experimental research, it was decided to use methods that had already been tested and well proven in musical pedagogical practice. These methods include visual and auditory display, comprehensive analysis of musical rhythm, compositions 
The development of a sense of rhythm in students in the process of choral conducting...

and artistic context creation, establishing the relationship between artistic and technical aspects on an intonational basis.

The initial level of rhythmic development of students included three types of research:

- study of the peculiarities of perception of the main components of musical rhythm - meter, tempo, rhythmic pattern, melody, dynamics;

- determination of psychomotor characteristics of students;

- identification of the main reference point in the perception of musical rhythm.

The nature and number of tasks were due to the need to obtain a holistic picture to determine the initial level of development of musical rhythm.

The quality of each task was assessed according to three indicators:

- by the accuracy of reproduction of rhythmic components;

- by the ability to determine the dominant components of the rhythm;

- according to the ability to motor improvisation, including the implementation of creative possibilities.

For each type of research, the goal, methodological techniques were determined, criteria for assessing the results of the development of a sense of musical rhythm and creative-motor activity were developed.

To study the perception of the main components of musical rhythm, students were offered the following tasks:

- reproduce an isolated rhythmic pattern;

- repeat the rhythmic pattern of the melody;

- display in a gesture the metric base of the performed piece in a variable size. 
The development of a sense of rhythm in students in the process of choral conducting...

In each piece of music, the student had to identify the regularities of the rhythmic organization, find support tones, rhythmic foundations and instabilities, establish the degree of divergence of rhythm and meter.

The condition for the first (control) part of the experiment was to determine the initial level of rhythm perception in junior students, taking into account the individuality of its perception by each of the students. At the same time, the psychomotor functions of each student were evaluated. When determining the initial level, each of the students evaluated such components of the rhythm as a meter, pace, rhythmic pattern, rhythm dynamics, rhythm melody.

This stage also included an assessment of students' accomplishments. The tasks included the following elements: the accuracy of student's reproduction of the proposed rhythmic components; the ability to determine among them the dominant; motor and plastic activity, in which creative opportunities are realized during conducting. The perception of the components of the musical rhythm by each student was evaluated on the basis of the following tasks: to play a specific rhythmic pattern, repeat the rhythmic pattern in the melody, and reproduce in a gesture the metric basis of the sounding symphony in a variable size. In addition, students identified discrepancies between the rhythm and the meter in each of the proposed works (Figures 1A-C). 
The development of a sense of rhythm in students in the process of choral conducting... Nan Xue

Figure 1. Motor and plastic activity in which creative possibilities of conducting are realized

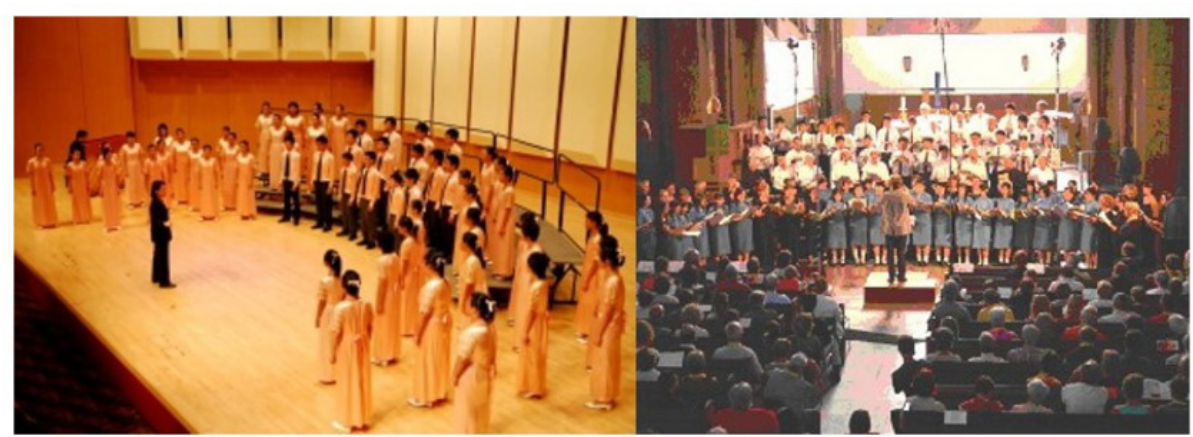

a

b

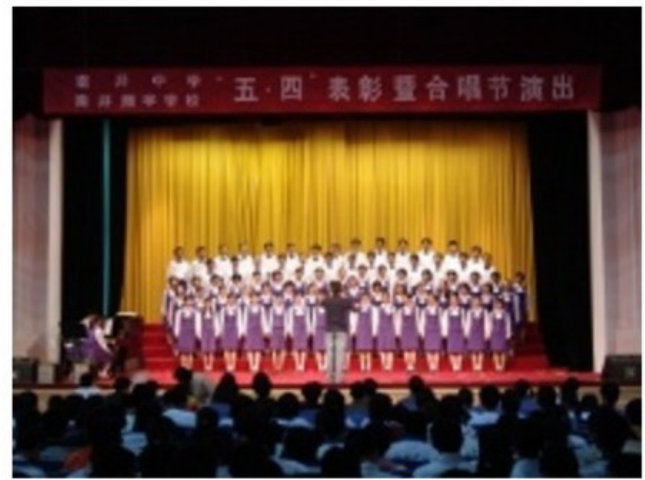

Students studied the works of the following composers: F. Liszt, R. Wagner, W. Furtwängler, H. Berlioz, O. Jeremiáš, L. Bernstein and others.

Psychomotor functions were evaluated as follows. When the proposed melody sounded, the student with the help of motor reactions had to reflect his/her understanding of the musical image. The authors took into account visual, auditory and motor reactions, while playing music, sharply contrasting works were chosen. The student through movements and gestures (like a future conductor) had to display such aspects of the rhythm and meter of the composition as dynamics, pace, accentuation, and others. When analyzing movements, the ability to improvise was taken into account, as well as the correspondence of the plasticity 
The development of a sense of rhythm in students in the process of choral conducting...

of movements to the rhythm characteristics of the sounding composition.

In the third, last stage of the experiment, a student survey was included. The questionnaires tested fundamental knowledge about rhythmic and musical development, as well as motivated students' interest in the art of conducting. In addition to the main questions regarding the subject being studied, the questionnaire had additional ones, which included questions about the student's attitude to conducting. The general level of students' culture and their psychological state were tested.

The second stage is experimental. The following tasks were included in this stage:

1. approbation of the model developed by the authors in terms of individual conducting lessons;

2. the detection and analysis of changes in students at the qualitative and quantitative levels after two stages of the experiment;

3. on the basis of the data obtained, in the case of confirmation of the hypothesis, make practical recommendations when teaching conducting students.

Work with students at this stage was organized on the basis of the individual characteristics of each student and their dominant abilities. A natural consequence of the educational process at this stage was increased attention to students with weaker preparation and the presence of students with high level of training that solve more complex problems.

If there were difficulties with the correct perception or interpretation of the rhythm, the program was adjusted to the main schedule.

At the end of the experiment, students passed an exam, the purpose of which was to establish the final results of their perception of rhythm and its elements, as well as the level of their conducting skills. 
The development of a sense of rhythm in students in the process of choral conducting... Nan Xue

\subsection{Statistical analysis}

Statistical data processing was performed using the program Past v. 3.0. Differences between traits were determined using the Fisher two-sample t-test (Choi, 2011) with a normal distribution of the trait and level of confidence $p \leq 0.05$.

\section{Results}

Questioning and practical exercises showed different levels of students' perception of a sense of rhythm (Table 1).

\section{Table 1. The results of the experiment and questionnaires of junior students on the subject of sense of rhythm}

\begin{tabular}{|l|l|l|l|}
\hline Experiment & Rhythm pace, \% * & Rhythm meter, \%* & Rhythm pulse, \%* \\
\hline $\begin{array}{l}\text { Control stage/ } \\
\text { questioning }\end{array}$ & 67 & 59 & 81 \\
\hline $\begin{array}{l}\text { Control stage/ } \\
\text { practical lessons }\end{array}$ & 42 & 48 & 61 \\
\hline $\begin{array}{l}\text { Experimental stage, } \\
\text { exam }\end{array}$ & 86 & 87 & 94 \\
\hline
\end{tabular}

As can be seen from the data in table 1, the questionnaire showed overestimated results. Thus, the results obtained in the questionnaires (regarding the rhythm rate) are 1.59 times higher than the results obtained in practice $(p \leq 0.01)$, on the rhythm meter -1.23 times ( $p \leq 0.05)$, and finally, on the rhythm pulse -1.32 times $(p \leq 0.05)$. The survey results, therefore, do not correspond to the actual data obtained. In the authors' opinion, more significant results were obtained when comparing indicators between control and experimental parts of the study: for the rhythm tempo -2.0 times (in favor of the part, at $p \leq 0.001$ ), for the rhythm meter -1.81 times $(p \leq 0.01)$, for the rhythm pulse -1.54 times (at $p \leq 0.05)$. The 
The development of a sense of rhythm in students in the process of choral conducting... Nan Xue

most significant changes have occurred in students' perception of the pace and meter of rhythm - the two main components of rhythm. These two components can be considered the determining factors affecting the development of a sense of musical rhythm in students. The third component - the perception of the rhythm pulse, exceeding the other two components (rhythm and meter, their divergence) - was most developed (in almost all students). From the results obtained, it can also be concluded about the effectiveness of the training program offered to students.

No less important results were obtained in the analysis of students' motor and plastic activity, as a reflection of their assimilation of conductor gestures (Table 2).

Table 2. Motor and plastic display of musical fragments by students

\begin{tabular}{|l|l|l|l|l|}
\hline Experiment stage & $\begin{array}{l}\text { Auditory } \\
\text { reaction }\end{array}$ & Motor reaction & Visual reaction & Combined reaction \\
\hline Control & 68 & 25 & 54 & 19 \\
\hline Experiment & 94 & 71 & 82 & 61 \\
\hline
\end{tabular}

The most prepared from the control stage of the experiment were the students with the auditory reaction-the difference with the experiment was only 1.38 times ( $p \leq 0.05$, in favor of the experiment). The most developed were motor and combined reactions - their indicators increased by $2.81(p \leq 0.001)$ and 3.21 times $(p \leq 0.001)$, respectively. The visual reaction took an intermediate position - its indicators increased 1.51 times $(p \leq 0.05)$. Thus, an increase in all three parameters - visual, motor, and auditory reactions - causes an increase in the combined reaction. This greatly facilitates the work of the future conductor, as he/she easily assimilates the features of the conductor gestures.

A comparison of control and experimental stages is shown in Figures 2 and 3. Figure 2 displays data on the development of rhythm in students. 
The development of a sense of rhythm in students in the process of choral conducting... Nan Xue

Figure 2. The development of a sense of rhythm in students in control and experimental stages

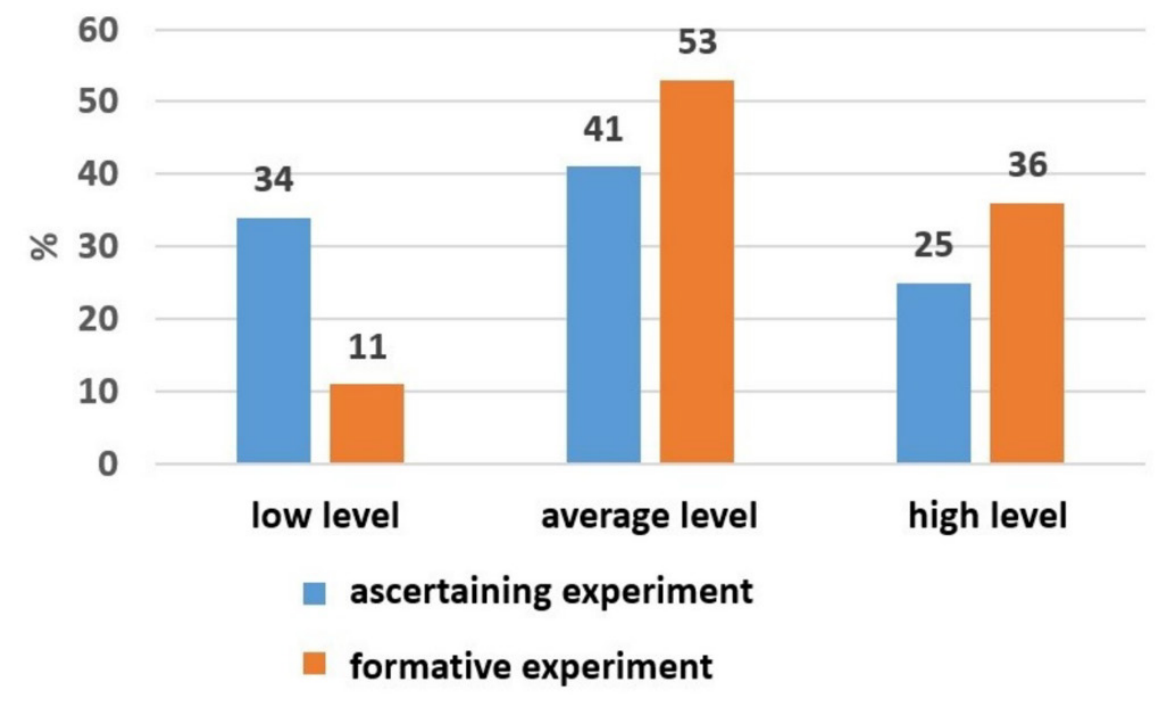

Figure 2 shows that the greatest progress in the development of sense of rhythm is achieved by students with a low level of sense of rhythm. That is, the number of students with a low sense of rhythm decreased by 3.1 times (in favor of control stage, $p \leq 0.001$ ). In two other groups - students with an average and high sense of rhythm, this indicator changed downward - an increase of 1.3 and 1.44 times, respectively (at $p \leq 0.05$, in favor of the experimental stage). That is, there was a significant increase in the number of students with an average and high sense of rhythm.

Similar data were obtained for indicators of intonation of the musical rhythm (Figure 3). Thus, in the group with a low level of intonation, these indicators decreased by 2 times ( $p \leq 0.01$, in favor of control stage), that is, half of the students from this group switched to the other two, with higher levels. 
The development of a sense of rhythm in students in the process of choral conducting... Nan Xue

Figure 3. Indicators of intonation of musical rhythm in students of different levels during control and experimental stages

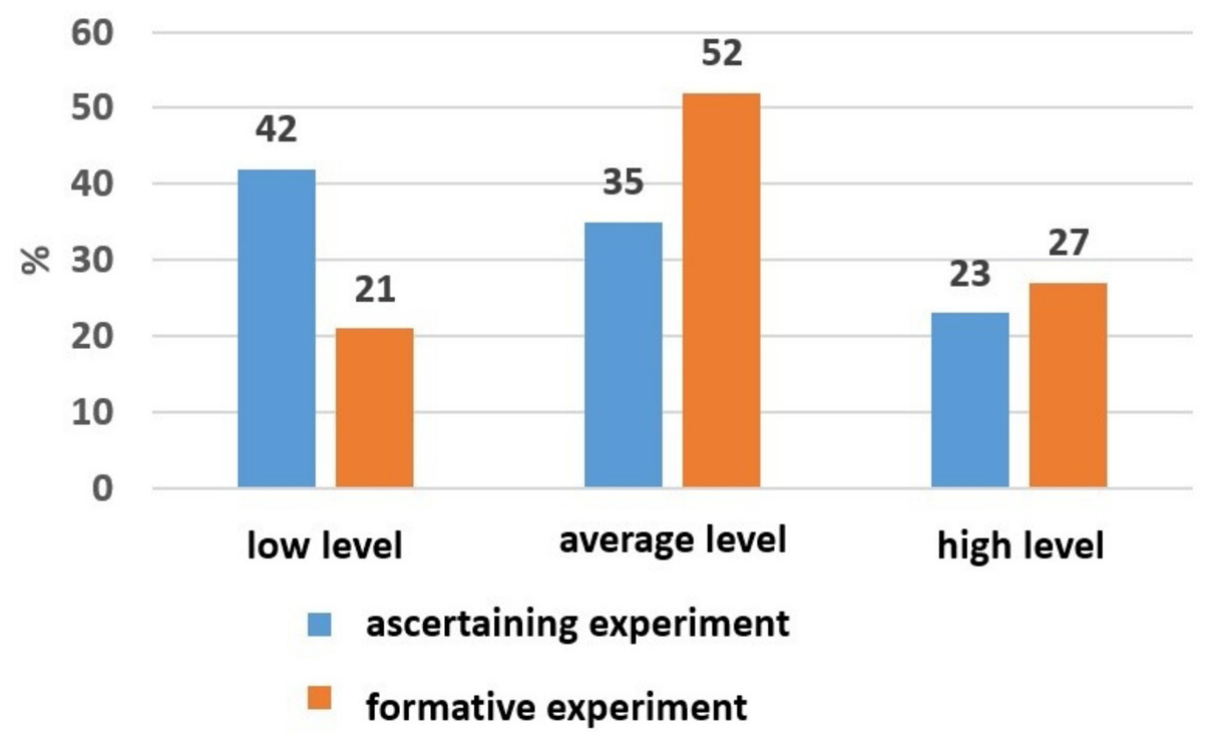

In groups with average and high levels, these indicators shifted less significantly -1.48 times ( $p \leq 0.05$, in favor of the experiment) and 1.17 times (the difference is unreliable), respectively.

Thus, for the main indicators of rhythmic perception, students have positive dynamics when comparing control and experimental results. The main role was played by individual conducting lessons. This indicates the correctness of the chosen strategy.

\section{Discussion}

Studies of scientific literature have shown that in musical practice, teachers deal mainly with conditional programs, where not only the physical, but also the mental nature of a person is important (Asaf'ev, 1982; McKay, 2015). Perceiving a sound or a sequence of sounds, the ear reacts to their dynamic and temporal relationships. Human motor activity is carried out with the help of many connections, where each link of this chain is important. Reliance on the general laws of psychophysiological research 
The development of a sense of rhythm in students in the process of choral conducting... Nan Xue

(Sechenov, 1956; Bernstein, 1990) allowed considering the conducting as a system that includes, on the one hand, the entire complex of psychological factors associated with the problems of creativity and management, and, on the other hand, automated skills, gestures and actions, through which the necessary artistic result is obtained. Movements become an external manifestation of mental processes that realize purposeful internal actions, therefore, the conductor's motor process cannot be isolated from the entire complex of creative activity, but must become an element of an integral system of professional actions, acquiring the status of "mental manifestations".

The system of rhythmic education of Émile Jaques-Dalcroze (Driver, 1958) is based on the same principles, which can be of great theoretical and practical importance for the successful development of musical rhythm in conditions of individual conducting lessons. While analyzing the concept of rhythmic education of JaquesDalcroze, a comparative description of his school with the system of François Delsarte was carried out (Porte, 1992), which allowed expanding understanding of the motor foundations of rhythm expression.

F. Delsarte's ideas played a certain role in the development of the theory and skills of expressive movements, which can still prove to be of practical importance for the development of correct and expedient movements in conducting. Jaques-Dalcroze, developing the system of $F$. Delsarte, created his own original school of rhythmic education. However, unlike F. Delsarte, whose laws of motion follow from the expressiveness of movement, the system of rhythmic education of Jaques-Dalcroze is based on the relationship between movement and music. Movements acquire their sense of music and become art through rhythm. JaquesDalcroze proceeded from the education of muscular tension and, in particular, of the nerve centers.

Considering the system of Jaques-Dalcroze, it can be noted that the importance of his teaching in the upbringing of a sense of rhythm lies in the installation and disclosure of the psychophysiological 
The development of a sense of rhythm in students in the process of choral conducting...

nature of human motor functions. His system is based on the concept of rhythm as a universal means of musical education, which organizes life in all its manifestations.

Unfortunately, in the modern practice of teaching conducting, the system of rhythmic education of $\mathrm{E}$. Jaques-Dalcroze through rhythmic exercises has not yet found its proper application. In his system, rhythm underlies any work, the entire fabric of a musical work is physically experienced and embodied in movement. In conducting, every gesture is born out of rhythm, and the body becomes an instrument for transmitting a piece of music in all its diversity. Concepts such as rhythm, freedom and naturalness of the apparatus, clarity of schemes and gestures, correctness, accuracy and expediency of movements are key in teaching conducting.

The methods of Jaques-Dalcroze, where the movements of the hands and body reflect the melodic rhythm, reacting to all aspects of the metro-rhythmic organization: accents, pauses, tempo, dynamics, etc., can be used in the work of conducting teachers for the development of conducting techniques.

The end of the experiment showed that students developed a full-fledged and comprehensive idea of both the rhythm as a whole and its components separately. Basic concepts were mastered and studied, both in practical and in theoretical aspects. The main thesis learned by students was the understanding of rhythm as the main factor contributing to the development of the technique of future conductors. The painstaking psychological and pedagogical work carried out by the teachers allowed the positive dynamics in motor plastics to appear and develop, as a means of manual conducting technique. All movements and plastic used by students as a conductor gestures were designed to free the essence of the musical composition, forming a continuous connection between the conductor, musicians and listeners. The nature of the movements has changed - they have acquired declamation, a greater degree of accuracy, freedom, emotionality and self-sufficiency. In addition, psychological guidelines have also changed - awareness of the movement towards the goal has appeared, qualities such 
The development of a sense of rhythm in students in the process of choral conducting... Nan Xue

as initiative and creative imagination have intensified. It is worth noting that this study showed that the development, under the guidance of music teachers and psychologists, allows one to achieve results, especially for the largest group of students - who have low sense of rhythm. The combination of actions according to the plan and individual conducting classes allowed the authors to achieve results that were 1.5-3.0 times higher than the initial ones (in control stage). The biggest changes occurred in the group of students with a low level of perception of rhythm. Here it is worth noting questionnaire data that are not quite adequate to the real situation. The authors believe that the questionnaire is applicable purely at the initial stage, so that further comparison with real data is possible.

The lessons not only increased the students' ability in terms of conducting art, but also allowed them to start the process of creative development of the personality as a whole. The results fully confirmed the hypothesis put forward in the phase of the experiment. Thus, the integrated approach, which consists in combining several factors previously not taken into account by other authors, made it possible to obtain impressive results in a deliberately short time frame. The factors included sensual, intellectual, motor-plastic and psychophysiological ones.

The essence of the developed methodological approaches is the thoughtful comprehensive development of a training program for students specializing in conducting and choral specialties. This includes such aspects as psychological, pedagogical, musiceducational (theoretical), applied music (practical). For the effective development of all the knowledge and practical skills offered in the learning process, it is necessary to "study" one's body, to know its capabilities and features. This allows achieving high results in plastic and movement, such freedom of movement allows the conductor gestures of conducting to develop. Similar data are available in similar studies (Gumm, 2012).

In addition, a significant role, as shown by the current one and other studies, is played by the psychophysiological factor, the 
The development of a sense of rhythm in students in the process of choral conducting... Nan Xue

individuality of each student (Williamson, 2013; Veronesi, 2014; Schiavio and Høffding, 2015; Pearce et al., 2016). Among them, a significant role is played by clocking, in particular, with rhythmic elements. Understanding the essence of the meter, rhythm and pulse is the key factor in the development of a musician (in particular, a conductor) as a person. Students understand music as a process associated with spatial and temporal dynamics. The embodiment of their creative individuality occurs in music, controlling the process of playing it, taking into account the individuality of the sound of each of the musicians, as well as the composer.

On the other hand, as shown by the data, the main development occurs at the experimental stage, when factors of self-expression in music, in its content and meaning, and especially in its rhythmic part, become paramount for the conductor.

Further work has wide prospects, since the relationship between individual conducting lessons based on a sense of rhythm on the one hand and other structures of the musical language on the other remains unexplored. The latter include the fret basis of music. This creates prospects for more effective teaching of conducting in the future.

\section{Conclusions}

The development of a sense of rhythm is directly related to the complexity of the approach in training future conductors, which includes such components as sensual, intellectual, logical, motor and psychophysiological. Practical comprehension of expressiveness and versatility of rhythm in each specific piece of music allows one to get a positive result.

The results can be used in theoretical developments, in particular, when creating a unified concept of rhythm, as well as in the development of psychological and pedagogical methods for the development of rhythm. The practical aspect of this study is 
The development of a sense of rhythm in students in the process of choral conducting... Nan Xue

the possibility of applying its results by conducting teachers. The results can be used in secondary schools specialized in music, or in universities, in practical classes on conducting. This work does not completely solve the problem of developing a sense of musical rhythm in the process of individual conducting classes for students of relevant specialties. At the same time, in the future, it is possible to study the influence of other components of music on the development of a sense of rhythm, in particular, the mode basis. In addition, a further search is necessary for effective methods designed to improve the educational process of conducting.

\section{References}

ASAF'EV, B. V. A Book about Stravinsky. Ann Arbor, Mich: UMI Research Press, 1982.

BERNSTEIN, N. A. Physiology of movement and activity. Moscow: Science, 1990.

BLACK, Marry. Bouncing and Dancing: The Use and Effect of Verbal Imagery in Choral Directing. In: GEISLER, U., and JOHANSSON, K. Choral Singing. Histories and Practices. Newcastle upon Tyne: Cambridge Scholars Publishing, 2014. p. 208-231.

BONSHOR, Michael J. Confidence and choral configuration: The affective impact of situational and acoustic factors in amateur choirs.

Psychology of Music, vol. 45, n. 5, p. 628-644, 2016.

CALDWELL, Cam, and HAYES, Lynda A. Self-efficacy and selfawareness: moral insights to increased leader effectiveness. Journal of Management Development, vol. 35, n. 9, p. 1163-1173, 2016.

CHENG-KANG, Z. Teaching and practice of high teacher's chorus conducting. Journal of Jiamusi Education Institute, vol. 7, p. 78, 2012. CHOI, Leena. Profile Likelihood: profile likelihood for a parameter in commonly used statistical models. R package version 1.1., 2011. 
The development of a sense of rhythm in students in the process of choral conducting... Nan Xue

CROSS, Ian. Music Analysis and Music Perception. Music Analysis, vol. 17, no. 1, p. 3-20, 1998.

DESMET, Frank, NIJS, Luc, DEMEY, Michiel, LESAFFRE, Micheline, MARTENS, Jean-Pierre, and LEMAN, Marc. Assessing a clarinet player's performer gestures in relation to locally intended musical targets. Journal of New Music Research, vol. 41, n. 1, p. 31-48, 2012. DRIVER, Ann. Music \& Movement. London, Oxford University Press, 1958.

EDWARDS, Anna. Gender and the Symphonic Conductor. Doctoral dissertation, University of Washington, 2015.

EDWARDS, Geoffrey, KISS, Jocelyne, MORALES, Ernesto, MCLAREN, Coralee, LACASSE, Serge, BOURBEAU, Marie Louise, FALCON, Juan Nino, and GUIMOND, Jonathan Proulx. Designing a Participatory and Interactive Opera. In: CVETKOVIĆ, D. Interactive MultimediaMultimedia Production and Digital Storytelling. London: IntechOpen, 2019. p. 1-24.

FOMINA, Anna. 2000. Song melody influence on speech intonation memorization. In: Proceedings of the sixth international conference on music perception and cognition. Keele, Staffordshire, UK: Department of Psychology. CD-ROM, 2000. p. 1-7.

GOD $\varnothing Y$, Rolf Inge. Understanding coarticulation in musical experience. In: Proceedings of the International Symposium on Computer Music Modeling and Retrieval. Cham: Springer, 2013. p. 535-547. GUMM, A. J. Six functions of conducting. Music Educators Journal, vol. 99, n. 2, p. 43-49, 2012.

HAMILTON, Rob. Musical Sonification of Avatar Physiologies, Virtual Flight and Gesture. In: ARAMAKI, M., DERRIEN, O., KRONLANDMARTINET, R., and YSTAD, S. Sound, Music, and Motion (CMMR 2013). Heidelberg: Springer, 2014. p. 517-532.

HANDELSMAN, M. The Underrepresentation of Women in the Field of Orchestral Conducting. Bloomington: Indiana University, Jacobs School of Music, 2017. 
The development of a sense of rhythm in students in the process of choral conducting... Nan Xue

HOLOMAN, Kern D. The Orchestra: A very Short Introduction.

Oxford: Oxford University Press, 2012.

HOPPER, Gill. Art, Education and Gender: The Shaping of Female Ambition. Cham: Springer, 2015.

KHANNANOV, Ildar. Boris Asafiev's intonatsia in the context of music theory of the 21st century. Rasprave, vol. 44, n. 2, p. 485-501, 2018.

KRAMANN, Guido. Generative Grammar Based on Arithmetic Operations for Realtime Composition. In: Proceedings of the 14th International Symposium on CMMR. Marseille, France, 2019. p. 346360.

MAES, Pieter-Jan, WANDERLEY, Marcelo M., and PALMER, Caroline. The role of working memory in the temporal control of discrete and continuous movements. Experimental Brain Research, vol. 233, n. 1, p. 263-273, 2015.

MCKAY, K. F. A contextual study of Boris Asafiev's Musical form as a process and and application of concepts to his Sonata for solo viola. Master Thesis. Faculty of Education and Arts, Western Australian Academy of Performing Arts (WAAPA), 2015.

MCQUERE, Gordon D. Russian Theoretical Thought in Music. UMI Research Press, 1983.

PALMER, Caroline. Music performance: Movement and coordination. In: DEUTSCH, D. The psychology of music. Cambridge, MA: Elsevier Academic Press, 2013. p. 405-422.

PEARCE, Eiluned, LAUNAY, Jacques, VAN DUIJN, Max, ROTKIRCH, Anna, DAVID-BARRETT, Tamas, and DUNBAR, Robin I. Singing together or apart: The effect of competitive and cooperative singing on social bonding within and between sub-groups of a university Fraternity. Psychology of Music, vol. 44, n. 6, p. 1255-1273, 2016.

PORTE, Alain. François Delsarte, une anthologie. Paris: IPMC, 1992. ROZE, Jocelyn, KRONLAND-MARTINET, Richard, ARAMAKI, Mitsuko, BOURDIN, Christophe, and YSTAD, Sølvi. Assessing the influence of constraints on cellists' postural displacements and musical expressivity. In: KRONLAND-MARTINET, R., ARAMAK, M., and YSTAD, S. International 
The development of a sense of rhythm in students in the process of choral conducting... Nan Xue

Symposium on Computer Music Multidisciplinary Research. Cham: Springer, 2015. p. 22-41.

ROZE, Jocelyn, ROZE, Jocelyn, ARAMAKI, Mitsuko, KRONLAND-MARTINET, Richard, and YSTAD, Solvi. Assessing the effects of a primary control impairment on the cellists' bowing gesture inducing harsh sounds. IEEE Access, vol. 6, p. 43683-43695, 2018.

SCHIAVIO, Andrea, and HØFFDING, Simon. Playing together without communicating? A pre-reflective and enactive account of joint musical performance. Musicae Scientiae, vol. 19, n. 4, p. 366-388, 2015.

SECHENOV, I. M. Theses. Izbrannye proizvedeniya, vol. 2, p. 864, 1956. TANG, Xiaobing. Radio, Sound Cinema, and Community Singing: The Making of a New Sonic Culture in Modern China. Twentieth-Century China, vol. 45, n. 1, p. 3-24, 2020.

THOMPSON, Marc R., and LUCK, Geoff. Exploring relationships between pianists' body movements, their expressive intentions, and structural elements of the music. Musicae Scientiae, vol. 16, n. 1, p. 19-40, 2012. VERONESI, Daniela. Correction sequences and semiotic resources in ensemble music workshops: The case of conduction. Social Semiotics, vol. 24, n. 4, p. 468-494, 2014.

WILLIAMSON, Douglass. Transformational leadership as jazz. Canadian Manager, vol. 38, n. 1, p. 17-19, 2013.

XINGGUI, Wen. On the Integration of Traditional Music Culture in Vocal Music Teaching in Colleges and Universities. In: 7th International

Education, Economics, Social Science, Arts, Sports and Management Engineering Conference (IEESASM 2019). Dalian, China, 2019. p. 642-645.

ZAK, Vladimir. Asaf'ev's Theory of Intonation and the Analysis of Popular Song. Popular Music, vol. 2, p. 91-111, 1982. 